\title{
Self-performed glansectomy and surgical repair by a nonpsychotic patient on androgen replacement therapy
}

\author{
Kirk Roth, MD; Jason Izard, MD; Darren Beiko, MD
}

\section{Abstract}

Genital self-amputation in men is a rare condition. We report an interesting case of penile self-amputation that was performed and surgically repaired by a nonpsychotic patient who was enrolled in a clinical trial for androgen replacement therapy. Using sterile technique for amputation of the glans penis and using cotton thread to suture the wound, the patient was able to avoid hemorrhage and infection. This is the first reported case of androgen therapyinduced penile self-amputation with patient-performed surgical reconstruction using primitive instruments.

Can Urol Assoc J 2009;3(4):E25-E28

\section{Introduction}

A 74-year-old man performed a penile self-amputation at the level of the distal shaft in an act of self-mutilation because of his strong religious beliefs. The patient managed the penile trauma himself, including suturing of the wound. Although he performed the amputation at home with primitive tools, he was able to avoid complications such as bleeding or infection, and only came to medical attention 1 week later during a routine follow-up visit for the clinical trial he was enrolled in. The case and a brief review of the literature are provided.

\section{Case report}

A 74-year-old born-again Christian man, divorced 30 years previously, was enrolled in an androgen replacement therapy clinical trial and presented for a routine follow-up appointment for the clinical trial. He had been enrolled in the clinical trial 3 months earlier and was randomly assigned to the dehydroepiandrosterone (DHEA) arm of the study. He was being treated with DHEA 50 mg orally twice per day. He mentioned a recent act of penile selfmutilation to the research associate, who promptly sent him to the emergency department for surgical and psychiatric assessment.

The patient was assessed at the emergency department,

now 7 days after self-amputation of his penis. He had a very vivid and descriptive recollection of the act and described it in great detail. In an attempt to maintain the sterility of his implements, he boiled his tools. He placed a metal clamp on the base of the shaft of his penis to prevent excessive bleeding. He poured bleach over a wooden block and covered it with a layer of antiseptic baby wipes. He placed his penis on the block and used 3 blows with a sterilized wood chisel to cut off his glans penis. He then used a boiled needle and cotton thread to sew the wound closed, leaving a small area open so that he could void. The glans was buried at an undisclosed location. Despite severe pain with urination over the next few days, he did not seek medical attention until 1 week later, after he had removed the stitches and the wound opened up on him.

On examination, the patient appeared well and was in no acute distress. His vital signs were stable. The glans was absent, and the wound base was clean with no discharge, and there was no erythema (Fig. 1). The distal end of each corporal body could just be seen behind granulation tissue. There was mild stenosis of the urethral orifice. On palpation, there was minimal tenderness.

The wound appeared to be healing well by secondary intention, and surgery was deemed unnecessary at the time. Replantation was certainly not an option given the delayed presentation and the fact that the amputated glans was buried at an undisclosed location.

The patient revealed that he had been troubled by frequent urges to masturbate, and sought to prevent further unwanted erections by cutting off his glans. He stated that he had made a promise to God to avoid masturbation. After repeatedly breaking his promise to God, he carefully planned out the act of amputating his own penis over a 1-year period. It was also revealed that he had been taking part in an androgen replacement study for the previous 3 months, but had not made the possible connection between his treatments and his increased libido.

Once the patient was cleared medically, a psychiatrist was consulted to assess his mental status because of the bizarre act of self-amputation. He was discharged home after it was decided that he was not a danger to himself or 
Roth et al.

others. The consultant psychiatrist specifically stated, "There was no evidence of psychosis, delirium or dementia. Patient has no past psychiatric history or family history of psychiatric illness. Patient's beliefs are in keeping with his community's beliefs."

Initial treatment consisted of wound cleansing and a Foley catheter for prevention of meatal stenosis. The patient was discharged home with a prescription for cephalexin $500 \mathrm{mg}$ orally 4 times per day and home care nursing visits were arranged for dressing changes twice per day and Foley catheter care. Despite some bladder spasm due to the

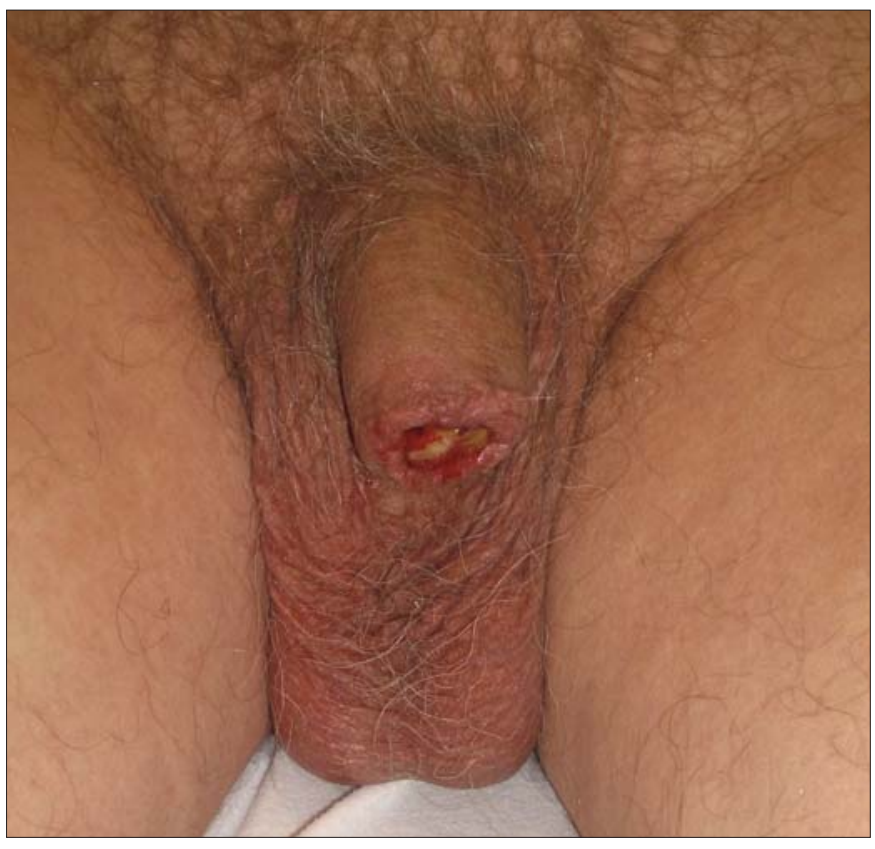

catheter, the patient had no immediate problems, and the catheter was removed after 1 month. However, he experienced a decreased stream during the next 3 months, and he used sterilized drill bits to perform urethral self-dilation. Ultimately this failed and he required meatal dilation and meatotomy for severe meatal stenosis (Fig. 2) almost 6 months after his initial presentation. Six months following his meatotomy, the patient was voiding fine with a widely patent urethral meatus (Fig. 3).

\section{Discussion}

Religious guilt has been previously reported in the literature as a contributing factor in penile self-mutilation. To our knowledge, androgen replacement therapy has

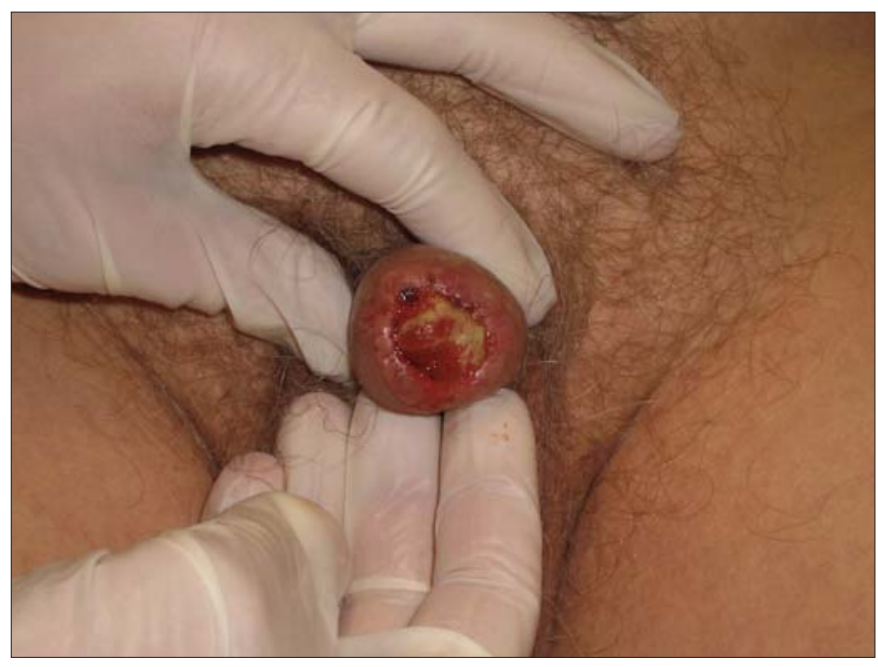

Fig. 1. Emergency department photographs showing healing wound 1 week following glans amputation.
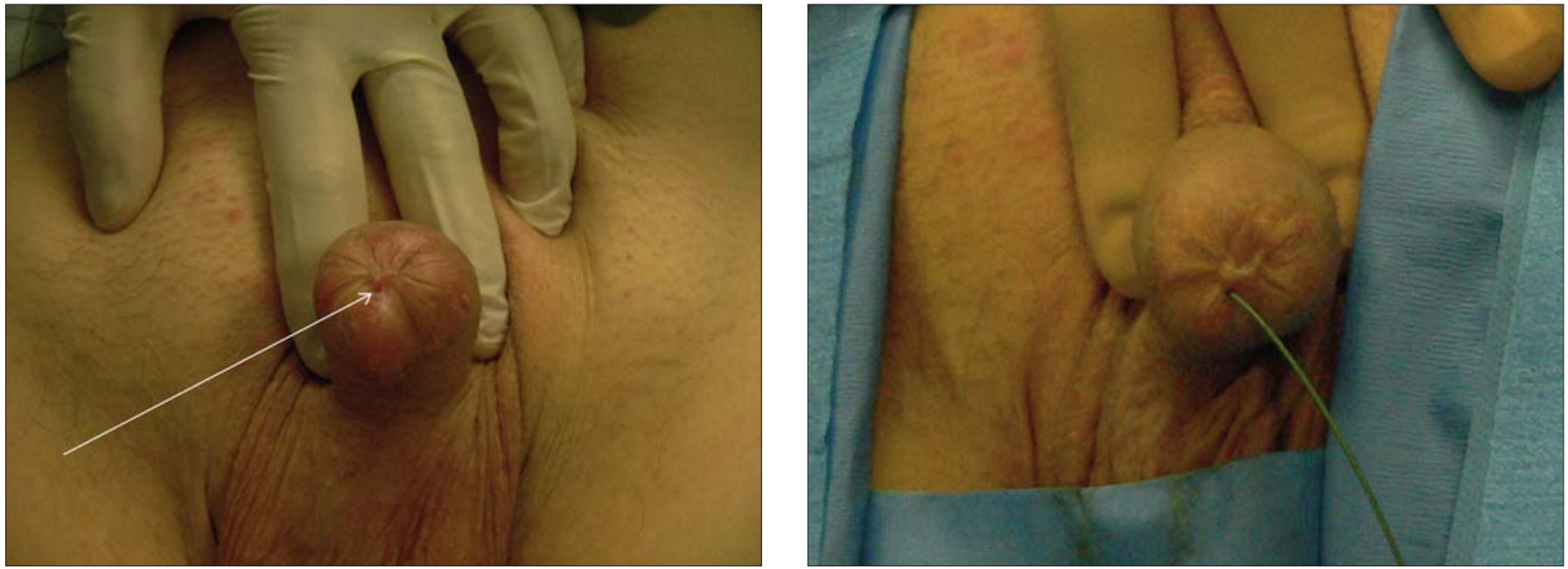

Fig. 2. Intraoperative photographs showing severe meatal stenosis (arrow points to meatus). 
not been previously reported as the cause of self-induced genital amputation. Previous cases of self-amputation have reported the use of the Internet for information on how to perform these acts. .,3 $^{3}$ However, our patient specifically stated that he did not use information from the Internet, because he feels that it has been "overrun by idiots" and especially disliked the fact that "information on the Internet is not peer reviewed." He stated that he used common sense in order to maintain sterility and hemostasis.

The patient's guilt over his sexual urges stemmed from his religious beliefs. However, he was also influenced by the writings of Dr. William Minor. Minor was an American surgeon who became famous for his contributions to the original Oxford English Dictionary while in an insane asylum. Minor apparently cut off his penis to relieve his guilt over his past womanizing.

When seen in follow-up, the patient gave us a photocopied

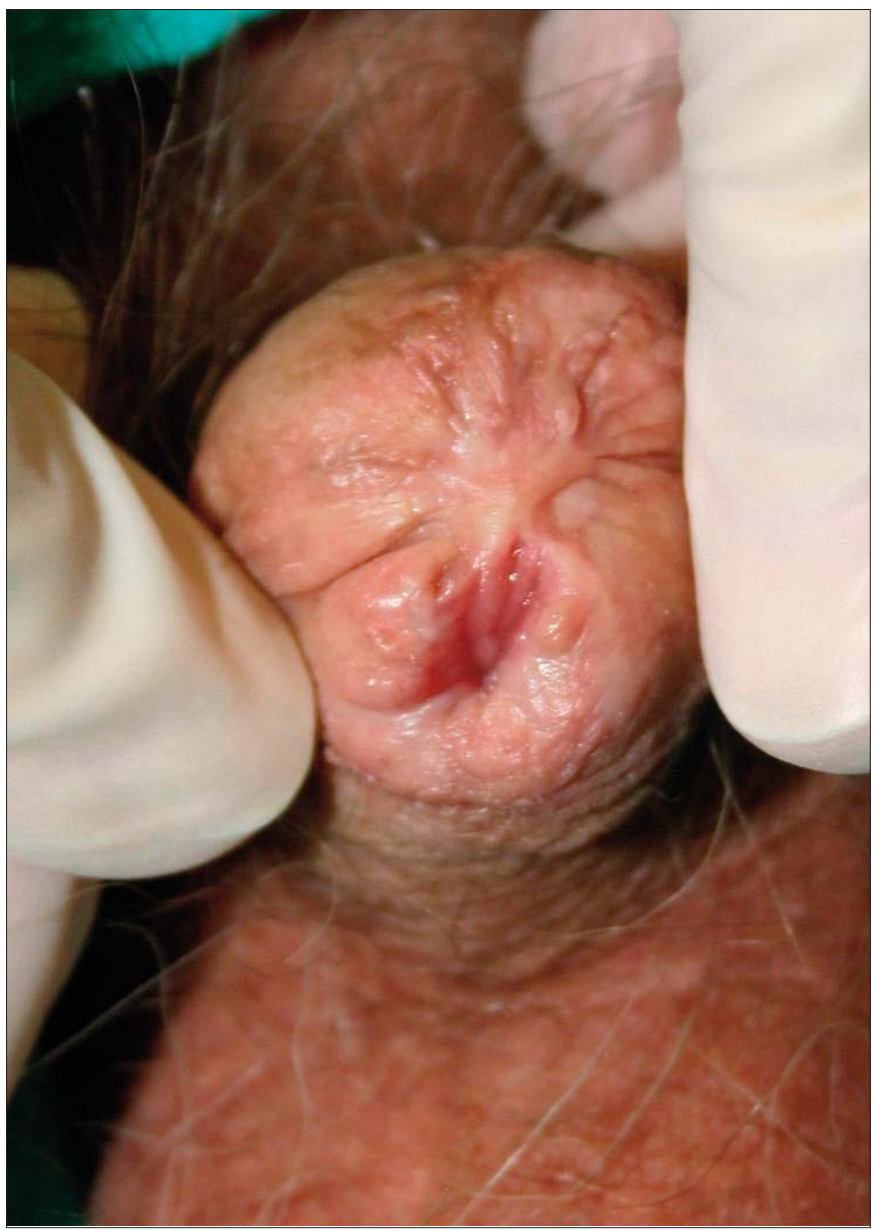

Fig. 3. Postoperative photograph 6 months after meatotomy, showing a patent urethral meatus. chapter of Simon Winchester's book The Professor and the Madman, which described the event. Like Dr. Minor, our patient felt that "the Deity would be satisfied that no further sexual rompings could take place." ${ }^{\prime 4}$

Penile self-amputation is an unusual presenting condition that often requires both surgical and psychiatric treatment. If the patient presents shortly after amputation, the amputated tissue is kept hypothermic until replantation can be attempted. ${ }^{\prime}$ However, in this case replantation was not possible because the glans had been buried at an undisclosed location and there was a 1-week delay in presentation. Although in this case there was no apparent underlying psychiatric disorder, there were 2 contributing identified factors that brought on this act of self-mutilation: religious guilt and androgen replacement therapy. The patient's religious guilt was based in part on a Bible verse, Matthew 18:8, "If your hand or your foot causes you to sin, cut it off and throw it away." Androgen replacement therapy results in an increase in libido, erections and masturbation. ${ }^{5}$ In the case of our patient, we believe that his initial urges to perform the act of self-mutilation were from his religious guilt, and the androgen replacement therapy resulted in an increase in masturbation, which prompted him to finally perform the act.

Owing to the care he took in attempting to use a sterile technique, the patient's penis was healing well without infection. He was followed up closely to ensure that the healing continued without infection, and to try to prevent future stricture formation. The patient displayed his forethought again by using sterilized drill bits to dilate his urethral meatus.

Review of the literature reveals the first case series of autocastration was reported in 1963 by Blacker and Wong, ${ }^{6}$ who identified 3 groups (schizophrenia, transvestism and complex religious or cultural beliefs) and 6 predisposing factors (impoverished childhood experiences, long and intense sexual confusion, submissive masochistic relationships with women, depression relieved by genital mutilation, strong feminine identification and repudiation of the penis). In 1979, Greilsheimer and Groves $^{7}$ reviewed 53 cases of genital self-mutilation by men and identified a psychotic state in $87 \%$, previous attempt in $19 \%$ and alcohol ingestion in $25 \%$. However, in 1996, Romilly and Isaac ${ }^{8}$ published a review of 98 cases of genital self-mutilation and found only $15 \%$ were related to psychotic symptoms.

Surgical options for penile self-amputation include replantation, tailoring of the penile stump and microsurgical free forearm flap phalloplasty. Replantation can only be performed if the patient seeks medical attention urgently and the glans is properly preserved under clean hypothermic conditions. 
Roth et al.

\section{Conclusion}

In summary, a nonpsychotic man on androgen replacement therapy with strong feelings of religious guilt due to masturbation successfully performed self-amputation of his glans penis unaided and without pain control. Despite his lack of medical skill or knowledge, and with the use of primitive equipment, he carried out the act without complications related to blood loss or infection. This is the first reported case of self-amputation of the penis as a complication of androgen replacement therapy.

From the Department of Urology, Queen's University, Kingston, Ont.

This article has been peer reviewed.

Competing interests: None declared.

\section{References}

1. Jezior JR, Brady JD, Schlossberg SM. Management of penile amputation injuries. World I Surg 2001; 25:1602-9.

2. Berger $B D$, Lehrmann $J A$, Larson $G$, et al. Nonpsychotic, nonparaphilic self-amputation and the internet. Compr Psychiatry 2005;46:380-3.

3. Master VA, McAninch JW, Santucci RA. Genital self-mutilation and the Internet. J Urol 2000;164:1656.

4. Winchester S. The professor and the madman. Markham (ON): HarperCollins; 1998. pp. 1-256.

5. Seidman SN. Hormonal aspects of sexual dysfunction: the therapeutic use of exogenous androgens in men and women. Curr Psychiatry Rep 2000;2:215-22.

6. Blacker KH, Wong N. Four cases of autocastration. Arch Gen Psychiatry 1963;8:169-76.

7. Greilsheimer H, Groves JE. Male genital self-mutilation. Arch Gen Psychiatry 1979;36:441-6.

8. Romilly CS, Isaac MT. Male genital self-mutilation. Br J Hosp Med 1996;55:427-31.

Correspondence: Dr. Darren Beiko, Department of Urology, Queen's University, Kingston General Hospital, 76 Stuart St., Kingston ON K7L 2V7; fax 613 545-1970; beikod@kgh.kari.net 